\title{
Bacteremia in hospitalized patients with human immunodeficiency virus: A prospective, cohort study Bekele Afessa ${ }^{* 1,2,3}$, Ian Morales ${ }^{2,3}$ and Bethany Weaver ${ }^{2,4}$
}

\begin{abstract}
Address: ${ }^{1}$ From the Division of Pulmonary and Critical Care, University of Florida Health Science Center, Jacksonville, Florida, USA, 2Department of Internal Medicine, University of Florida Health Science Center, Jacksonville, Florida, USA, 3Current affiliations Division of Pulmonary and Critical Care Medicine and Internal Medicine, Mayo Clinic, 200 First Street SW, Rochester, MN USA and 4Current affiliations Division of Allergy and Infectious Diseases, Department of Medicine, University of Washington, Box 35931, Seattle, WA 98104, USA

E-mail: Bekele Afessa* - afessa.bekele@mayo.edu; Ian Morales - morales.ian@mayo.edu; Bethany Weaver - bethanyg@u.washington.edu *Corresponding author
\end{abstract}

This article is available from: http://www.biomedcentral.com/I47I-2334/I//3

(c) 200 I Afessa et al; licensee BioMed Central Ltd. Verbatim copying and redistribution of this article are permitted in any medium for any non-commercial purpose, provided this notice is preserved along with the article's original URL. For commercial use, contact info@biomedcentral.com

\begin{abstract}
Background: Bacterial infections complicate the course of patients with human immunodeficiency virus infection. The purpose of this study was to describe the bacterial pathogens causing blood stream infection, identify the risk factors for the development of blood stream infection and determine the impact of blood stream infection on the outcome of patients infected with human immunodeficiency virus.
\end{abstract}

Methods: The incidence, etiology, risk factors and outcome of bacterial blood stream infection were prospectively determined in 1,225 consecutive hospitalizations of adults with human immunodeficiency virus infection.

Results: Blood stream infection occurred in 88 hospitalizations (7\%); 73 of 89 infections (82\%) were community acquired. The most commonly isolated gram-positive organism was Streptococcus pneumoniae (2I); gram-negative, Escherichia coli (14). Blood stream infection was detected in $8 \%$ of African Americans and $22 \%$ of Hispanics compared with $2 \%$ of whites $(P=0.0013)$. Patients with blood stream infection had higher white blood cell counts (median, 6.5 vs. $4.9 \times 109 / \mathrm{L} ; P=0.0002$ ) and mortality $(18 \%$ vs. $4 \% ; P<0.000 I)$ than patients without infection.

Conclusions: In patients with human immunodeficiency virus, blood stream infection is associated with an increased mortality rate. Recognition of the incidence, etiology, and risk factors of blood stream infection in patients with human immunodeficiency virus infection could lead to measures that reduce the increased mortality.

\section{Background}

The importance of bacterial infections that complicate the clinical course of patients with human immunodeficiency virus (HIV) infection has been recognized since the beginning of the AIDS epidemic [1,2]. Several factors predispose patients with HIV infection to bacterial infec- tions. These factors include abnormalities in humoral and cell-mediated immunity, phagocytic cell dysfunction, and skin and mucous membrane defects [3]. The presence of neutropenia $[4,5]$ use of central venous catheters $[4,6]$, low $\mathrm{CD} 4^{+}$lymphocyte count, and intravenous drug use [6] are cited as risk factors for bacteremic infec- 
tions in patients with HIV infection. Bacterial infections are responsible for the immediate cause of death of up to $30 \%$ of patients with HIV infection [7]. The purpose of this study was to describe the bacterial pathogens causing blood stream infection, identify the risk factors for the development of blood stream infection, and determine the impact of blood stream infection on the outcome of hospitalized patients with HIV.

\section{Methods}

This prospective, observational study included 1,225 consecutive hospital admissions of 599 adults with HIV infection treated at the University Medical Center, Jacksonville, Florida, from April 1995 through March 1998. All adults with HIV infection who were admitted to the hospital were included in the study. The University Medical Center is a 528-bed, inner-city teaching hospital affiliated with the University of Florida. Because of the hospital's inner-city location, most of the patients were African American. The need for informed consent was waived by the institutional review board of the hospital.

The isolation of a bacterium in 1 or more blood cultures was diagnostic of bacterial blood stream infection. Blood isolates of coagulase-negative staphylococci, Corynebacterium species, Bacillus species, Propionibacterium species, Peptostreptococcus species, Clostridium species, and unidentified Gram-positive rods were considered contaminated if a single blood culture yielded the organism or the clinician did not initiate treatment, considering it not a true infection. Mycobacterial infections were excluded from the study. The place of acquisition of the blood stream infection was defined as nosocomial if the infection developed after 48 hours of hospitalization or within 14 days of previous hospitalization. We collected data on age, sex, race, exposure category for HIV infection, place of acquisition, white blood cell count, $\mathrm{CD} 4^{+}$ lymphocyte count, worst Acute Physiology and Chronic Health Evaluation (APACHE) II score within 24 hours of hospital admission, presence of blood stream infection, intensive care unit admission status, length of hospital stay, and in-hospital mortality. The source of the blood stream infection was identified by the isolation of the same pathogenic organism from both the source and the blood. The APACHE II score and predicted mortality rate for each hospital admission were calculated [8]. The standardized mortality ratio was determined by dividing the actual mortality by the predicted mortality. For the purpose of this study, each admission was analyzed independently.

StatView 5.0 computer software (SAS Institute, Cary, NC) was used for statistical analysis. Each mean was expressed with its standard deviation. Comparisons between groups were made using logistic regression analysis and Student $t$, Mann-Whitney $U, \mathrm{X}^{2}$, and Fisher exact tests. When available, the continuity-corrected $P$ values were used for $\mathrm{X}^{2}$ analysis. $P$ values less than 0.05 were considered significant.

\section{Results}

Table 1 provides demographic, exposure category, and health status data on 1,225 hospital admissions of 599 patients with HIV infection. Because some individuals were admitted more than once during the study period, in this report the word patient does not necessarily mean 1 unique individual. Thirty-four percent of the African Americans and $67 \%$ of the Hispanics had a history of injection drug use compared with $20 \%$ of the whites $(P<$ o.0001).

Table I: Demographic Characteristics.

\begin{tabular}{lc}
\hline Characteristic & Value $^{\mathrm{a}}$ \\
\hline & \\
Age, mean \pm SD, y & $38.2 \pm 8.9$ \\
Sex & \\
Male & $754(62)$ \\
Female & $471(38)$ \\
Race & \\
African American & $1,026(84)$ \\
White & $190(16)$ \\
Hispanic & $9(\leq 1)$ \\
Exposure category & \\
Injection drug use & $333(27)$ \\
Heterosexual contact & $194(16)$ \\
Homosexual contact & $138(11)$ \\
Commercial sex work and injection drug & $32(3)$ \\
use & \\
Homosexual contact and injection drug & $30(2)$ \\
use & \\
Commercial sex work & $29(2)$ \\
Blood transfusion & $22(2)$ \\
Needle stick & $1(<1)$ \\
Unidentified & $446(36)$ \\
CD4 ${ }^{+}$lymphocyte count, mean \pm SD & \\
(median), $\times$I09/L & $0.159 \pm 0.223(0.060)$ \\
APACHE II score, mean \pm SD (median) & $15 \pm 7(14)$ \\
&
\end{tabular}

APACHE, Acute Physiology and Chronic Health Evaluation; HIV, human immunodeficiency virus; SD, standard deviation. aValues are number (percentage) unless otherwise indicated.

In the 1,225 admissions, 88 patients (7\%) had 89 episodes of blood stream infection. Of these 89 infections, $73(82 \%)$ were community acquired and $16(18 \%)$ were nosocomial. Twenty-one of the 345 admissions (6\%) during the first year of the study had blood stream infection compared with 35 of 435 admissions (8\%) during the second year and 32 of 445 admissions (7\%) during the third year $(P=0.5748)$. The sources of bacteremia 
Table 2: Bacterial Pathogens Causing Blood Stream Infection in Hospitalized Patients With HIV Infection

\begin{tabular}{lcc}
\hline Pathogen & $\begin{array}{c}\text { Community } \\
\text { acquired, no. }\end{array}$ & $\begin{array}{c}\text { Nosoco- } \\
\text { mial, no. } \\
(n=16)\end{array}$ \\
\hline Gram-negative bacteria & & \\
Escherichia coli & 30 & 5 \\
Pseudomonas aeruginosa & 13 & 1 \\
Salmonella typhi & 3 & 3 \\
Enterobacter cloacae & 6 & 0 \\
Acinetobacter baumanii & 2 & 0 \\
Proteus vulgaris & 1 & 0 \\
Aeromonas hydrophila & 1 & 0 \\
Haemophilus influenzae & 0 & 1 \\
Pseudomonas stutzeri & 1 & 0 \\
Proteus mirabilis & 1 & 0 \\
Klebsiella pneumoniae & 1 & 0 \\
Gram-positive bacteria & 1 & 0 \\
Streptococcus pneumoniae & 43 & 11 \\
Staphylococcus aureus & 19 & 2 \\
Enterococcus species & 8 & 4 \\
Streptococcus viridans & 5 & 3 \\
Coagulase-negative Staphylococcus & 2 & 2 \\
Streptococcus equisimilis & 1 & 0 \\
Group C Streptococcus species & 1 & 0 \\
Nonhemolytic Streptococcus species & 1 & 0 \\
& & \\
\hline
\end{tabular}

HIV, human immunodeficiency virus.

were identified in 52 patients (59\%) and included pneumonia in 33, urinary tract infection in 12, peritonitis in 2 , and cellulitis, pancreatitis, central venous catheter, cholangitis, and arthritis in 1 each. In 1 patient, 2 organisms, Salmonella typhi and Klebsiella pneumoniae, were isolated from the blood during the same hospitalization; both were community acquired. The pathogens causing blood stream infection are listed in Table 2. Six patients had 2 episodes of blood stream infection during the study period, all during different hospitalizations. One patient had 2 episodes of Pseudomonas aeruginosa bacteremia and another patient had 2 episodes of $S$ typhi bacteremia.

There were no significant differences in age, sex, and risk factors for HIV infection between patients with and without blood stream infection (Table 3). The median $\mathrm{CD} 4^{+}$ lymphocyte count for injection drug users was $0.08 \times$ $109 / \mathrm{L}$ compared with $0.06 \times 109 / \mathrm{L}$ for noninjection drug users $(P=0.0042)$. The incidence of blood stream infection in African Americans and Hispanics was higher than in whites (Table 3 ). The $\mathrm{CD} 4^{+}$lymphocyte count was similar and the APACHE II score and white blood cell count higher in patients with blood stream infection compared with those without blood stream infection (Table 3). In patients with blood stream infection, $78 \%$ had a CD4 $4^{+}$lymphocyte count less than $0.2 \times 10^{9} / \mathrm{L}$ compared with $74 \%$ of the patients without blood stream infection $(P=0.5649)$. The predicted mortality rate of patients with blood stream infection was higher than that of patients without blood stream infection (37\% vs. 21\%; $P<0.0001$ ). Twenty-six percent of the patients with blood stream infection had a white blood cell count less than $4 \times 109 / \mathrm{L}$ compared with $36 \%$ of the patients without blood stream infection $(P=0.0810)$.

The differences in the length of hospital stay, intensive care unit admission rate, and in-hospital mortality between patients with and patients without blood stream infection are listed in Table 4. Compared with patients without blood stream infection, the in-hospital mortality and intensive care unit admission rates of patients with blood stream infection were higher and their length of hospital stay longer. The standardized mortality ratios of patients with and without blood stream infection were 0.486 and 0.213 , respectively. Multiple logistic regression analysis using a model consisting of mortality as a dependent variable and APACHE II score and presence of blood stream infection as independent variables showed that both blood stream infection (odds ratio, 2.29; 95\% CI, 1.13-4.62) and APACHE II score (odds ratio, 1.18; 95\% CI, 1.14-1.23) were independently associated with mortality. Among patients with blood stream infection, survivors had a lower APACHE II score than nonsurvivors (median, 17 vs. 27.5; $P<0.0001$ ), but did not significantly differ in $\mathrm{CD}_{4}^{+}$lymphocyte count (median, 0.077 vs. $0.011 \times 10^{9} / \mathrm{L} ; P=0.0574$ ). Two of the 34 patients (6\%) with gram-negative blood stream infection died compared with 14 of 54 patients (26\%) with grampositive blood stream infection $(P=0.0366)$. The mortality associated with each pathogen causing blood stream infection is listed in Table 5. Among the 88 patients with blood stream infection, multiple logistic regression analysis using a model of mortality as a dependent variable and APACHE II score, $\mathrm{CD}_{4}^{+}$lymphocyte count, and place of acquisition of the infection as independent variables showed that higher APACHE II scores (odds ratio, 1.25; 95\% CI, 1.12-1.40) and nosocomial acquisition (odds ratio, 5.85; 95\% CI, 1.25-27.31), but not $\mathrm{CD}_{4}{ }^{+}$lymphocyte count (odds ratio, 1.00; 95\% CI, 0.99-1.00), were independently associated with mortality. The intensive care unit admission rate of patients with community-acquired blood stream infection was similar to that of patients with nosocomial blood stream infection ( $19 \%$ vs. $44 \% ; P=0.0820$ ). The median length of hospital stay of patients with community-acquired blood stream infection was 5 days compared with 8.5 days for patients with nosocomial blood stream in- 
Table 3: Differences in Age, Sex, Race, Exposure Category, CD4+ Lymphocyte Count, and APACHE II Score

\begin{tabular}{|c|c|c|c|}
\hline \multirow[b]{2}{*}{ Characteristic } & \multicolumn{2}{|c|}{ Blood stream infection ${ }^{a}$} & \multirow[b]{2}{*}{$P$} \\
\hline & Present $(n=88)$ & Absent $(n=1,137)$ & \\
\hline Age, mean $\pm S D, y$ & $38.3 \pm 9.3$ & $38.2 \pm 8.9$ & 0.9261 \\
\hline Sex & & & 0.4045 \\
\hline Male & $50(7)$ & $704(93)$ & \\
\hline Female & $38(8)$ & $433(92)$ & \\
\hline Race & & & 0.0013 \\
\hline African American & $83(8)$ & $943(92)$ & \\
\hline White & $3(2)$ & $187(98)$ & \\
\hline Hispanic & $2(22)$ & $7(78)$ & \\
\hline Exposure category & & & 0.4231 \\
\hline Injection drug use & $23(7)$ & $310(93)$ & \\
\hline Heterosexual contact & $19(10)$ & $175(90)$ & \\
\hline Homosexual contact & $3(2)$ & $135(98)$ & \\
\hline Commercial sex work and & $2(6)$ & $30(94)$ & \\
\hline \multicolumn{4}{|l|}{ injection drug use } \\
\hline Homosexual contact and & $2(7)$ & $28(93)$ & \\
\hline \multicolumn{4}{|l|}{ injection drug use } \\
\hline Commercial sex work & $2(7)$ & $27(93)$ & \\
\hline Blood transfusion & I (5) & $21(95)$ & \\
\hline Needle stick & $0(0)$ & $I(100)$ & \\
\hline Unidentified & $36(8)$ & $410(92)$ & \\
\hline $\begin{array}{l}\mathrm{CD} 4^{+} \text {lymphocyte count, } \\
\text { mean } \pm \mathrm{SD}(\text { median }), \times 10^{9} / \mathrm{L}\end{array}$ & $0.173 \pm 0.278(0.059)$ & $0.158 \pm 0.218(0.060)$ & 0.6967 \\
\hline $\begin{array}{l}\text { White blood cell count, } \\
\text { mean } \pm \text { SD }(\text { median }), \times 10^{9} / \mathrm{L}\end{array}$ & $9.0 \pm 6.6(6.5)$ & $6.3 \pm 4.6(4.9)$ & 0.0002 \\
\hline $\begin{array}{l}\text { APACHE II score, } \\
\text { mean } \pm \text { SD (median) }\end{array}$ & $19.8 \pm 7.9(18)$ & $14.3 \pm 6.6(13)$ & $<0.0001$ \\
\hline
\end{tabular}

APACHE, Acute Physiology and Chronic Health Evaluation; SD, standard deviation. aValues are number (percentage) unless otherwise indicated.

fection $(P=0.0477)$. The mortality rate of patients with blood stream infection was $6 \%$ during the third year of the study compared with $14 \%$ and $31 \%$ during the first and second years, respectively $(P=0.0247)$.

Table 4: Differences in Length of Hospital Stay, ICU Admission Rate, and In-hospital Mortality

\begin{tabular}{lccc}
\hline & \multicolumn{3}{c}{ Blood stream infection $^{\mathrm{a}}$} \\
\cline { 2 - 3 } & $\begin{array}{c}\text { Present } \\
(n=88)\end{array}$ & $\begin{array}{c}\text { Absent } \\
(n=1,137)\end{array}$ & $P$ \\
Characteristic & & & \\
\hline & & & \\
$\begin{array}{l}\text { Length of hospital stay, } \\
\text { mean } \pm \text { SD (median), d }\end{array}$ & $\begin{array}{c}8.7 \pm 9.3(6) \\
21(24)\end{array}$ & $\begin{array}{c}6.0 \pm 6.3(4) \\
112(10)\end{array}$ & $<.0003$ \\
$\begin{array}{l}\text { ICU admission } \\
\text { In-hospital mortality }\end{array}$ & $16(18)$ & $51(4)$ & $<0.000$ I \\
& & & \\
\hline
\end{tabular}

ICU, intensive care unit; SD, standard deviation. aValues are number (percentage) unless otherwise indicated.

\section{Discussion}

This study describes the incidence of bacterial blood stream infection as well as its causative pathogens, risk factors for its development, and its impact on outcome in hospitalized patients with HIV. Blood stream infection developed in $7 \%$ of the patients; of these infections, $82 \%$ were community acquired and $18 \%$ were nosocomial. The incidence rate of blood stream infection was higher in African Americans and Hispanics compared with whites. There were no significant differences in sex, age, and $\mathrm{CD}_{4}{ }^{+}$lymphocyte count between patients with and patients without blood stream infection. The APACHE II score and white blood cell count of patients with blood stream infection were higher than those of patients without blood stream infection. The mortality and ICU admission rates of patients with blood stream infection were higher and their length of hospital stay longer than those of patients without blood stream infection. Among patients with blood stream infection, the mortality rate 
of the community-acquired group was lower than that of the nosocomial group.

\begin{tabular}{|c|c|c|}
\hline Pathogen & $\begin{array}{c}\text { Survivors, } \\
\text { no. } \\
\text { (\%) }(n=72)\end{array}$ & $\begin{array}{c}\text { Nonsurvivors, } \\
\text { no. } \\
(\%)(n=16)\end{array}$ \\
\hline Gram-negative bacteria & $32(94)$ & $2(6)$ \\
\hline Escherichia coli & $14(100)$ & 0 \\
\hline Pseudomonas aeruginosa & $6(100)$ & 0 \\
\hline Salmonella typhi & $5(100)$ & 0 \\
\hline Enterobacter cloacae & I (50) & $\mathrm{I}(50)$ \\
\hline Acinetobacter baumanii & $\mathrm{I}(100)$ & 0 \\
\hline Proteus vulgaris & $I(100)$ & 0 \\
\hline Aeromonas hydrophila & $\mathrm{I}(100)$ & 0 \\
\hline Haemophilus influenzae & $I(100)$ & 0 \\
\hline Pseudomonas stutzeri & $\mathrm{I}(100)$ & 0 \\
\hline Proteus mirabilis & 0 & $\mathrm{I}(100)$ \\
\hline Klebsiella pneumoniae and S typhi & $\mathrm{I}(100)$ & 0 \\
\hline Gram-positive bacteria & $40(74)$ & $14(26)$ \\
\hline Streptococcus pneumoniae & $18(86)$ & $3(14)$ \\
\hline Staphylococcus aureus & $7(58)$ & $5(42)$ \\
\hline Enterococcus species & $7(87)$ & $1(13)$ \\
\hline Streptococcus viridans & $6(75)$ & $2(25)$ \\
\hline Streptococcus equisimilis & $I(100)$ & 0 \\
\hline Coagulase-negative Staphylococcus & I (50) & I (50) \\
\hline Group C Streptococcus species & 0 & $I(100)$ \\
\hline Nonhemolytic Streptococcus species & 0 & $\mathrm{I}(100)$ \\
\hline
\end{tabular}

HIV, human immunodeficiency virus.

Bacteremia is more common in hospitalized HIV-positive patients than in HIV-negative patients [9]. The incidence of nonmycobacterial bacteremias in hospitalized patients with HIV ranges from 2\% to 9\% [10-12]. Most blood stream infections in patients with HIV are community acquired $[13,14]$. In developed countries, the incidence rate of HIV-associated bacteremia has declined after the introduction of highly active antiretroviral therapy (HAART) $[14,15]$. In the present study, the incidence of blood stream infection among hospitalized patients with HIV was $7 \%$, and most of these infections were community acquired. Despite the availability of HAART during the later period of our study, we did not find a decline in the rate of bacteremia in our patient population. However, the mortality rate of the patients with blood stream infection declined during the third year of the study, reflecting the potential benefit of HAART.

African American race, Hispanic race, and high APACHE II score were found to be risk factors for blood stream infection in hospitalized patients with HIV infection in the present study. Because there were only few Hispanics in the present study and the African Americans were more likely than the whites to be injection drug users, we do not think there is an independent association between race and bacteremia. Previous studies have shown injection drug use to be a risk factor for bacteremia $[6,14]$. However, like the study by Tumbarello et al. [16], our study did not find injection drug use to be a risk factor for blood stream bacterial infection. The earlier stage of HIV infection in the injection drug users in our study may explain their lower bacteremia rate. Neutropenia is reported to be a risk factor for the development of bacterial infection in patients with HIV infection $[4-6,14,16]$. However, in our study, neither the prevalence of leukopenia nor the total white blood cell count was lower in patients with blood stream bacterial infection compared with patients without blood stream bacterial infection. In fact, the white blood cell count was higher in patients with than in patients without bacterial blood stream infection. Unlike other studies, which showed the $\mathrm{CD} 4^{+}$ lymphocyte count to be low in HIV-positive patients with blood stream bacterial infection $[6,16]$, the $\mathrm{CD}^{+}$lymphocyte count did not differ between patients with and patients without bacterial blood stream infection in the present study. The lack of association between bacteremia and low $\mathrm{CD} 4^{+}$lymphocyte count or leukopenia in the present study may reflect the earlier stage of HIV infection in our patient population.

Previous studies have shown the presence of central venous catheters to be a risk factor for bacterial blood stream infection $[4,6,11,14,16,17]$. In the present study, an intravascular catheter was the source of the blood stream infection in only 1 patient; this was probably due to infrequent use of central venous catheters and shorter length of hospital stay. As in the study by Tumbarello et al. [14], higher severity of illness, measured by APACHE II score, was associated in the present study with the development of bacterial blood stream infection.

The common sources of blood stream infection in patients with HIV infection include the lungs, skin, subcutaneous tissue, and intravascular catheters $[12,13,18,19]$. In the present study, the most common source of bacteremia was pneumonia.

Gram-positive bacteria are responsible for most of the bacteremias in hospitalized HIV-positive patients [14]. More gram-positive than gram-negative organisms were isolated from the blood stream of our subjects. Many studies have shown Staphylococcus species to be the most common isolates in blood $[6,11,13,16,20]$. In our study Streptococcus pneumoniae was the most common isolate. The rate of pneumococcal bacteremia is about 100-fold higher in patients with than in patients without 
HIV infection [21]. Because most of the blood stream infections were community acquired and the most common source of infection was pneumonia, Staphylococci were less frequent than $S$ pneumoniae and Escherichia coli.

$P$ aeruginosa is being recognized more frequently as causing both community-acquired and nosocomial bacteremia in patients with HIV infection $[13,16,18,20,22,23]$. Hospitalization, neutropenia, antibiotic therapy, steroid use, and low $\mathrm{CD}_{4}^{+}$lymphocyte count are risk factors for $P$ aeruginosa bacteremia in patients with HIV infection [22,24]. Previously, we reported that $P$ aeruginosa is the most common pathogen causing bacterial pneumonia in our patients [25]. However, compared with pneumococcal pneumonia, Pseudomonas pneumonia is less likely to be associated with bacteremia [25]. The annual incidence rate of $P$ aeruginosa infection in patients with HIV infection is estimated to be 2.51 cases per 100 admissions [22]. $P$ aeruginosa has been reported to be the causative agent of $7.6 \%$ to $18 \%$ of bacteremias in hospitalized patients with HIV infection $[14,16,20]$. In the present study, $P$ aeruginosa was responsible for $6 \%$ of the bacteremias.

In patients with HIV infection, although bacteremia in general is more frequently associated with growth of gram-positive pathogens, genitourinary sepsis is more frequently related to the detection of gram-negative bacteria [26]. Our finding of $E$ coli to be the most common gram-negative organism differs from findings in previous studies. In a recent study of blood stream infection of hospitalized patients with HIV, E coli was not even mentioned among the common etiologic agents [14]. In the present study a significant number of the patients with blood stream infection were women, who are at higher risk for genitourinary infection. The relatively high number of women may explain the high rates of $E$ coli blood stream infection in our study.

The present study showed that the presentation with or the development of blood stream infection in hospitalized patients with HIV leads to poor outcome, as evidenced by increased mortality, length of hospital stay, and intensive care unit admission rate. Hospital mortality rates of HIV-positive patients with blood stream infection range from $9 \%$ to $63 \%[6,9,11-14,16]$. In the present study, the hospital mortality rate of patients with blood stream infection was $16 \%$. Among patients with blood stream infection, we found the association of increased mortality with high APACHE II score and hospital acquisition of the infection, but not with low $\mathrm{CD}_{4}^{+}$ lymphocyte count. Because nosocomial bacteremia is likely to develop in patients with a complicated hospital course and lead to multiple organ dysfunction, its associ- ation with an increased mortality rate is not surprising. Previous studies of HIV-positive patients with blood stream infection have shown that a high APACHE II score predicts an increased risk of death [14,27]. Although we did not find a significant association between mortality and $\mathrm{CD} 4^{+}$lymphocyte count, a previous study showed that a low $\mathrm{CD}_{4}^{+}$lymphocyte count is associated with increased mortality in patients with nosocomial blood stream infection [27].

Our study has several limitations. The risk factors for HIV infection were not identified in $36 \%$, most probably because of the health care providers' and patients' lack of openness with regard to sexual activity. Because we were unable to document the patients' antiretroviral therapy and previous antimicrobial treatment or chemoprophylaxis, we could not assess their impact on the incidence, etiology, and outcome of bacterial blood stream infection. In many patients, the source of the blood stream infection was not identified. Finally, because the study was limited to a single center, the results may not apply to other patient populations.

\section{Conclusions}

Bacteremia occurs in $7 \%$ of adult patients with HIV infection who require admission to the hospital. Most of the bacteremias are community acquired. The most common gram-positive organism isolated from the blood stream of patients with HIV infection is $S$ pneumoniae, and the most common gram-negative organism is $E$ coli. The APACHE II score of patients with blood stream infection is higher than that of patients without blood stream infection. The presence of blood stream infection is associated with an increased mortality rate, length of hospital stay, and intensive care unit admission rate. Recognition of the incidence, etiology, and risk factors of blood stream infection in patients with HIV infection can lead to preventive and therapeutic measures that may reduce the associated increased mortality and morbidity.

\section{Competing interests}

None declared.

\section{References}

I. Whimbey E, Gold JW, Polsky B, Dryjanski J, Hawkins C, Blevins A Brannon P, Kiehn TE, Brown AE, Armstrong D: Bacteremia and fungemia in patients with the acquired immunodeficiency syndrome. Ann Intern Med 1986, 104:5। I-514

2. Northfelt DW, Polsky B: Bacteremia in persons with HIV infection. AIDS Clin Rev 199159-79

3. Kovacs A, Leaf HL, Simberkoff MS: Bacterial infections. Med Clin North Am 1997, 81:319-343

4. Keiser P, Higgs E, Smith J: Neutropenia is associated with bacteremia in patients infected with the human immunodeficiency virus. Am J Med Sci 1996, 3 I 2: I I8-122

5. Moore RD, Keruly JC, Chaisson RE: Neutropenia and bacterial infection in acquired immunodeficiency syndrome. Arch Intern Med 1995, 155:1965-1970

6. Meyer CN, Skinhoj P, Prag J: Bacteremia in HIV-positive and AIDS patients: incidence, species distribution, risk-factors, 
outcome, and influence of long-term prophylactic antibiotic treatment. Scand J Infect Dis 1994, 26:635-642

7. Stein M, O'Sullivan P, Wachtel T, Fisher A, Mikolich D, Sepe S, Fort G, Carpenter C, Skowron G, Mayer K: Causes of death in persons with human immunodeficiency virus infection. Am J Med 1992, 93:387-390

8. Knaus WA, Draper EA, Wagner DP, Zimmerman JE: APACHE II: a severity of disease classification system. Crit Care Med 1985, 13:818-829

9. Vugia DJ, Kiehlbauch JA, Yeboue K, N'Gbichi JM, Lacina D, Maran M, Gondo M, Kouadio K, Kadio A, Lucas SB, et al: Pathogens and predictors of fatal septicemia associated with human immunodeficiency virus infection in Ivory Coast, west Africa. J Infect Dis 1993, 168:564-570

10. Frank U, Daschner FD, Schulgen G, Mills J: Incidence and epidemiology of nosocomial infections in patients infected with human immunodeficiency virus. Clin Infect Dis 1997, 25:3 I8-320

II. Fichtenbaum CJ, Dunagan WC, Powderly WG: Bacteremia in hospitalized patients infected with the human immunodeficiency virus: a case-control study of risk factors and outcome. I Acquir Immune Defic Syndr Hum Retrovirol 1995, 8:51-57

12. Krumholz HM, Sande MA, Lo B: Community-acquired bacteremia in patients with acquired immunodeficiency syndrome: clinical presentation, bacteriology, and outcome. Am J Med 1989, 86:776-779

13. Bonadio M, Gigli C, Maccanti O, Longo B, Smorfa A: Bloodstream infections in HIV-positive patients: a review of sixty-eight episodes. I Chemother 1998, 10:243-247

14. Tumbarello M, Tacconelli E, Donati KG, Citton R, Leone F, Spanu T, Cauda R: HIV-associated bacteremia: how it has changed in the highly active antiretroviral therapy (HAART) era. J Acquir Immune Defic Syndr 2000, 23:| 45-15I

15. Manfredi R, Nanetti A, Ferri M, Chiodo F: HIV-associated non-mycobacterial sepsis-bacteraemia, before and during the highly active antiretroviral therapy era (letter). AIDS 1999, 13:12741276

16. Tumbarello M, Tacconelli E, Caponera S, Cauda R, Ortona L: The impact of bacteraemia on HIV infection. Nine years experience in a large Italian university hospital. J Infect 1995, 3 I:I23|3|

17. Hickey MM, Shanson DC: Septicaemia in patients with and without AIDS at Westminster Hospital, London. J Infect I993, 27:243-250

18. Mendelson MH, Gurtman A, Szabo S, Neibart E, Meyers BR, Policar M, Cheung TW, Lillienfeld D, Hammer G, Reddy S, et al: Pseudomonas aeruginosa bacteremia in patients with AIDS. Clin Infect Dis 1994, | 8:886-895

19. Omenaca C, Turett G, Yarrish R, Astiz M, Lin R, Kislak JW, Cadden $\mathrm{J}$ : Bacteremia in HIV-infected patients: short-term predictors of mortality. J Acquir Immune Defic Syndr 1999, 22: 155-160

20. Edge MD, Rimland D: Community-acquired bacteremia in HIVpositive patients: protective benefit of co-trimoxazole. AIDS 1996, 10:1635-1639

21. Redd SC, Rutherford GW III, Sande MA, Lifson AR, Hadley WK, Facklam RR, Spika JS: The role of human immunodeficiency virus infection in pneumococcal bacteremia in San Francisco residents. J Infect Dis 1990, 162:1012-1017

22. Meynard JL, Barbut F, Guiguet M, Batisse D, Lalande V, Lesage D, Guiard-Schmid JB, Petit JC, Frottier J, Meyohas MC: Pseudomonas aeruginosa infection in human immunodeficiency virus infected patients. J Infect 1999, 38:176-|8|

23. Manfredi R, Nanetti A, Ferri M, Chiodo F: Pseudomonas spp. complications in patients with HIV disease: an eight-year clinical and microbiological survey. Eur J Epidemiol 2000, 16: I I I- I I8

24. Vidal F, Mensa J, Martinez JA, Almela M, Marco F, Gatell JM, Richart C, Soriano E, Jimenez de Anta MT: Pseudomonas aeruginosa bacteremia in patients infected with human immunodeficiency virus type I. Eur J Clin Microbiol Infect Dis 1999, 18:473-477

25. Afessa B, Green B: Bacterial pneumonia in hospitalized patients with HIV infection: the Pulmonary Complications, ICU Support, and Prognostic Factors of Hospitalized Patients with HIV (PIP) Study. Chest 2000, I I7:1017-1022

26. Manfredi R, Costigliola P, Ricchi E, Chiodo F: Sepsis-bacteraemia and other infections due to non-opportunistic bacterial pathogens in a consecutive series of 788 patients hospitalized for HIV infection. Clin Ter 1993, 143:279-290
27. Tumbarello M, Tacconelli E, Donati KG, Leone F, Morace G, Cauda $\mathrm{R}$, Ortona L: Nosocomial bloodstream infections in HIV-infected patients: attributable mortality and extension of hospital stay. J Acquir Immune Defic Syndr Hum Retrovirol 1998, 19:490497
Publish with BioMed Central and every scientist can read your work free of charge

"BioMedcentral will be the most significant development for disseminating the results of biomedical research in our lifetime." Paul Nurse, Director-General, Imperial Cancer Research Fund Publish with BMC and your research papers will be: - available free of charge to the entire biomedical community - peer reviewed and published immediately upon acceptance - cited in PubMed and archived on PubMed Central

- yours - you keep the copyright 